\title{
Graft Interpenetrating Polymer Networks of Bismaleimide and Epoxy Based on Maleimide-Terminated Polyurethane-Grafted Epoxy
}

\author{
Jin-Lin $\mathrm{HAN}^{\dagger}$ and Kun-Yih LI* \\ Department of Chemical Engineering, National I-Lan Institute of Agriculture and Technology. I-Lan. Taiwan \\ * Department of Chemical Engineering, National Taiwan University, Taipei, Taiwan
}

(Received June 11, 1998)

\begin{abstract}
This work used maleimide-terminated polyurethane-grafted epoxy, or epoxy-graft-maleimide-terminated polyurethane (EGMPU), based on poly (butylene adipate) (EGMPU(PBA)) and poly(propylene oxide) (EGMPU(PPG)) as a coupling agent to synthesize graft interpenetrating polymer networks of bismaleimide (BMI) and the diglycidyl ether of bisphenol A (epoxy) (BMI/epoxy/graft(EGMPU)-IPN). Infrared (IR) analysis was performed to characterize the coupling agents EGMPU. The stress-strain properties of the BMI/epoxy/graft(EGMPU)-IPNs were studied. Dynamic mechanical analysis (DMA) showed that the EGMPU(PBA) coupling agent has better grafting effect due to higher compatibility between the BMI and epoxy networks than the EGMPU(PPG) coupling agent in BMI/epoxy/graft(EGMPU)-IPNs.

KEY WORDS Bismaleimide / Epoxy/Graft Interpenetrating Polymer Networks / Mechanical Properties / Dynamic Mechanical Analysis /
\end{abstract}

Many feasible systems have been developed using interpenetrating polymer network (IPN) structure. $^{1-3}$ According to previous investigations, the mechanical properties of polymer materials with IPN structures are superior to those of ordinary polymers. ${ }^{4-7}$ In particular, the IPN structure enhances the compatibility of polymer network materials. ${ }^{8}$ Although the cured 4,4'-bis(maleimidodiphenylmethane) (BMI) possesses excellent thermal stability, it is brittle and difficult due to high crosslinking density. ${ }^{9-11}$ The cured epoxy by tertiary amine shows excellent mechanical properties and processibility is good. ${ }^{12}$ Our previous works enhanced mechanical properties by synthesizing graft interpenetrating polymer networks of polyurethane and epoxy (PU/epoxy graftIPN $)^{14.15}$ and interpenetrating the polymer network of bismaleimide and polyurethane-crosslinked epoxy (BMI/ PU-EP IPN). ${ }^{16.17}$ Processes for preparing IPNs can be generally classified as sequential and simultaneous polymerizations. ${ }^{12}$

This work used the maleimide-terminated polyurethane-grafted epoxy, or epoxy-graft-maleimide-terminated polyurethane (EGMPU), based on poly(butylene adipate) (EGMPU(PBA)) and poly(propylene oxide) (EGMPU(PPG)) as a coupling agent to synthesize the graft interpenetrating polymer networks of bismaleimide
(BMI) and diglycidyl ether of bisphenol A (epoxy) (BMI/epoxy/graft(EGMPU)-IPN). To improve the mechanical properties of epoxy resin, the BMI resin is introduced and EGMPU partially grafted to the epoxy resin. Simultaneous bulk polymerization is used to prepare graft-IPNs. Stress-strain and dynamic mechanical properties of these graft-IPNs were investigated.

\section{EXPERIMENTAL}

\section{Materials}

Table I lists the materials used in the experiments. Polyols (PPG400, PPG1000, PPG2000, PBA700, PBA1000, PBA2000) and epoxy resin (diglycidyl ether of bisphenol A, DGEBA, EEW = 186) were heated at $60^{\circ} \mathrm{C}$ and degassed by vacuum overnight before use.

\section{Preparation of Polyurethane (PU) Prepolymers}

PU prepolymers were prepared by reacting $4,4^{\prime}$-diphenyl methane diisocyanate (MDI) with polyols. MDI ( 2 equivalent weight) was initially poured to a reaction kettle and heated to melting state. Polyols in proper amounts ( 1 equivalent weight) were poured into the reaction kettle. The mixture was vigorously agitated by a mechanical stirrer.

Table I. Materials

\begin{tabular}{|c|c|c|}
\hline Designation & Description & Source \\
\hline PBA700 & Poly(butylene adipate)glycol MW $=700$ & Tai Gin Co., Taiwan \\
\hline PBA 1000 & Poly(butylene adipate) glycol $\mathrm{MW}=1000$ & Tai Gin Co., Taiwan \\
\hline PBA2000 & Poly(butylene adipate) glycol $\mathrm{MW}=2000$ & Tai Gin Co., Taiwan \\
\hline PPG400 & Poly(propylene oxide)glycol MW $=400$ & ARCO Chem. Co., Taiwan \\
\hline PPG1000 & Poly(propylene oxide)glycol MW $=1000$ & ARCO Chem. Co., Taiwan \\
\hline PPG2000 & Poly( propylene oxide)glycol MW $=2000$ & ARCO Chem. Co., Taiwan \\
\hline DGEBA & Diglycidyl ether of bisphenol A, EEW $=186, n=0.11267$ & Dow-Chemical Co. U.S.A. \\
\hline TDMP & 2,4,6-Tri(dimethyl aminomethyl)phenol & Ciba-Geigy Co. Switzerland \\
\hline DCPO & Dicumyl peroxide & Merk Co., Germany \\
\hline BMI & 4,4'-Bis(maleimide diphenylmethane) & Merk Co., Germany \\
\hline
\end{tabular}

\footnotetext{
+ To whom all correspondence should be addressed.
} 
The reactions occurred under dry nitrogen atmosphere at a temperature of approximately $68^{\circ} \mathrm{C}$. The isocyanate content of the reaction mixture was determined by di- $n$-butyl amine titration methods. ${ }^{13}$ The reactions were terminated when the isocyanate content reached a theoretical value.

\section{Preparation of Maleimide-Terminated Polyurethane-} Grafted Epoxy (EGMPU)

The maleimide-terminated polyurethane-grafted epoxy, or EGMPU, was synthesized by a two-step reaction. First, the condensation reaction of maleic anhydride and NCO-terminated PU prepolymer was performed as follows:

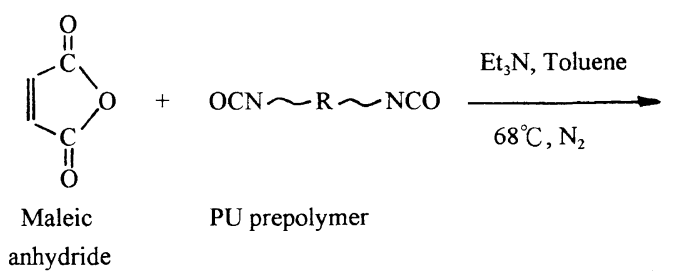<smiles>O=C1C=CC(=O)N1C[R]N([O-])[O-]</smiles>

where $\mathrm{R}$ is the urethane-terminated polyether or polyester diols.

PU prepolymers were mixed with maleic anhydride, at a mole ratio of $1: 1$, in toluene (solvent) and to which was added $1 \mathrm{wt} \%$ (based maleic anhydride) triethylamine (TEA) catalyst. The reaction occurred under dry nitrogen atmosphere at $68^{\circ} \mathrm{C}$. Start of the reaction was observed by the evolution of $\mathrm{CO}_{2}$ gas. During this period, samples were drawn for infrared analysis. The reaction was terminated when the intensity of the - NCO absorption peak at $2270 \mathrm{~cm}^{-1}$ was reduced to a constant intensity and $\mathrm{C}=\mathrm{O}$ (of acid anhydride) absorption peak at $1848 \mathrm{~cm}^{-1}$ disappeared. Secondly, the solution was poured into the epoxy resin (DGEBA, DER331) after removing TEA and the residual isocyanate group (-NCO) of the solution was reacted with the secondary hydroxyl group of the DGEBA resin $(\mathrm{NCO} / \mathrm{OH}=1: 1)$ to form the urethane linkage. Maleimide-terminated polyurethane-grafted epoxy, or EGMPU, was formed. The reaction was as follows:

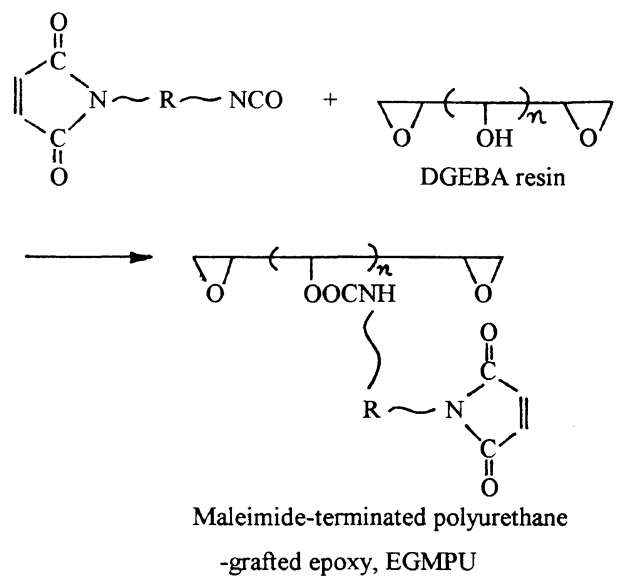

During this period, samples were drawn for infrared (IR) analysis. The reaction was stopped when the $-\mathrm{NCO}$ absorption peak at $2270 \mathrm{~cm}^{-1}$ disappeared. A slightly viscous liquid was obtained after removing the solvent by vacuum. The EGMPU based on PPG (EGMPU(PPG)) and PBA (EGMPU(PBA)) was used as a coupling agent for the graft interpenetrating polymer networks of BMI and epoxy.

\section{Preparation of Graft Interpenetrating Polymer Networks of BMI and Epoxy Based on EGMPU Coupling Agent (BMI/Epoxy/Graft(EGMPU)-IPNs)}

An appropriate amount of the epoxy resin (DGEBA) was mixed with different amounts of BMI and placed in a cup. $10 \mathrm{wt} \%$ of the above coupling agent EGMPU, 3 phr of curing agent (2,4,6-tri(dimethyl aminomethyl) phenol, TDMP) and $1 \mathrm{wt} \%$ of initiator (dicumyl peroxide, DCPO) were added to the mixture. After mechanical agitation and degassing for $30 \mathrm{~s}$, the mixture was cast into an aluminum mold at $120^{\circ} \mathrm{C}$ and pressed for $1 \mathrm{~h}$. Finally, it was further heated to $180^{\circ} \mathrm{C}$ for $2 \mathrm{~h}$. Following removal from the mold, the samples were stored in a desiccator where relative humidity was maintained at $50 \%$ for at least 3 days.

\section{Testing Methods}

Infrared spectra were taken with a Hitachi 270-30 infrared spectrophotometer. A sample was directly applied by dabbing it onto a $\mathrm{KBr}$ pellet.

Stress-strain properties were determined using a Tensilon TCF-RC universal test unit. The ASTM-D638 test procedure was followed at a crosshead speed of $1 \mathrm{~cm} \mathrm{~min}^{-1}$.

Dynamic mechanical analysis (DMA) was performed on a DuPont 983 DMA unit from $-100^{\circ} \mathrm{C}$ to $250^{\circ} \mathrm{C}$. Frequency was set at $110 \mathrm{~Hz}$ and sample dimensions were $6 \times 1 \times 0.2 \mathrm{~cm}$.

\section{RESULTS AND DISCUSSION}

\section{Infrared Spectroscopy}

Initially, the reaction (eq 1) between PU prepolymer and maleic anhydride was monitored by disappearance of the characteristic peak of acid anhydride $\left(1848 \mathrm{~cm}^{-1}\right)$ in IR spectra, as shown in Figure 1. That $\mathrm{C}=\mathrm{O}$ stretching vibration peak of acid anhydride disappears at 1848 $\mathrm{cm}^{-1}$ and intensity of the $-\mathrm{NCO}$ absorption peak decreases at $2270 \mathrm{~cm}^{-1}$ in the IR spectra confirm that the reaction occurred between the isocyanate and maleic anhydride. Characteristic carbonyl absorption peaks of imides appeared at $1748 \mathrm{~cm}^{-1}$. Elemental analysis of the products provided further evidence that an imide group formed after evolution of a stoichiometric amount of $\mathrm{CO}_{2}$. According to Figure 2, introducing the reaction products of the eq 1 into the DGEBA resin gradually reduced the absorption peak of -NCO group at 2270 $\mathrm{cm}^{-1}$ in intensity with reaction time. The peak disappeared over an extended period. This implies that the reaction between the residual $-\mathrm{NCO}$ group of the reaction products of the eq 1 and pendent secondary hydroxyl group of DGEBA resin was complete. The maleimide-terminated polyurethane-grafted epoxy, or EGMPU, coupling agent thus apparently formed. 


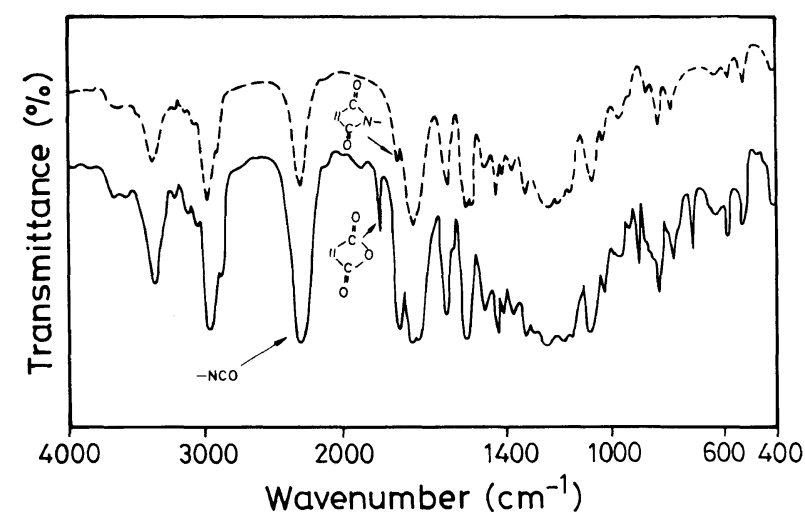

Figure 1. IR spectra during reaction of PU(PBA1000) prepolymer with maleic anhydride: (-) beginning of reaction; (-.-.-) end of reaction.

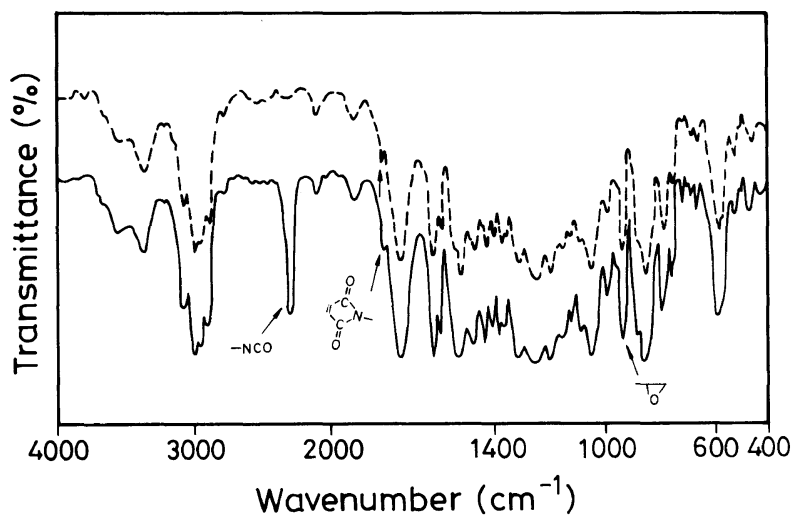

Figure 2. IR spectra during reaction of maleimide-terminated PU(PBA 1000) prepolymer with DGEBA resin: (-) beginning of reaction; (--.--) end of reaction.

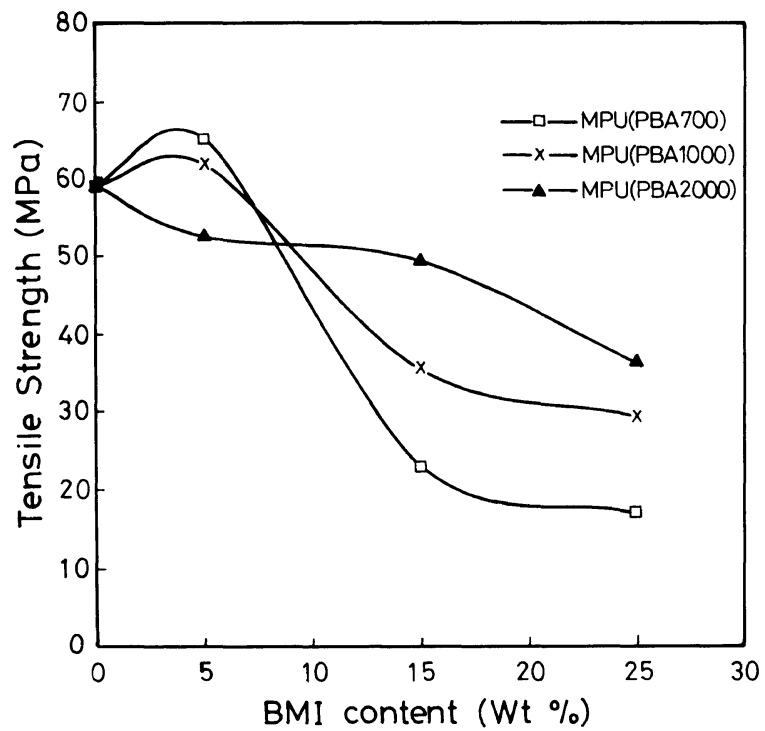

Figure 3. Tensile strength of BMI/epoxy/graft(EGMPU(PBA))-IPN vs. BMI content (BMI/epoxy/coupling agent $=5 / 95 / 10,15 / 85 / 10$, 25/75/10 wt. ratio): ( $\square$ ) BMI/epoxy/graft(EGMPU(PBA700))-IPN; (×) BMI/epoxy/graft(EGMPU(PBA1000))-IPN; (A) BMI/epoxy/ graft(EGMPU(PBA2000))-IPN.

\section{Stress-Strain Properties}

Tensile strength for both of BMI/epoxy/graft(EGMPU)-IPN, those from $10 \mathrm{wt} \%$ EGMPU based on PBA (EGMPU(PBA)) coupling agent (Figure 3) and Polym. J., Vol. 31, No. 5, 1999

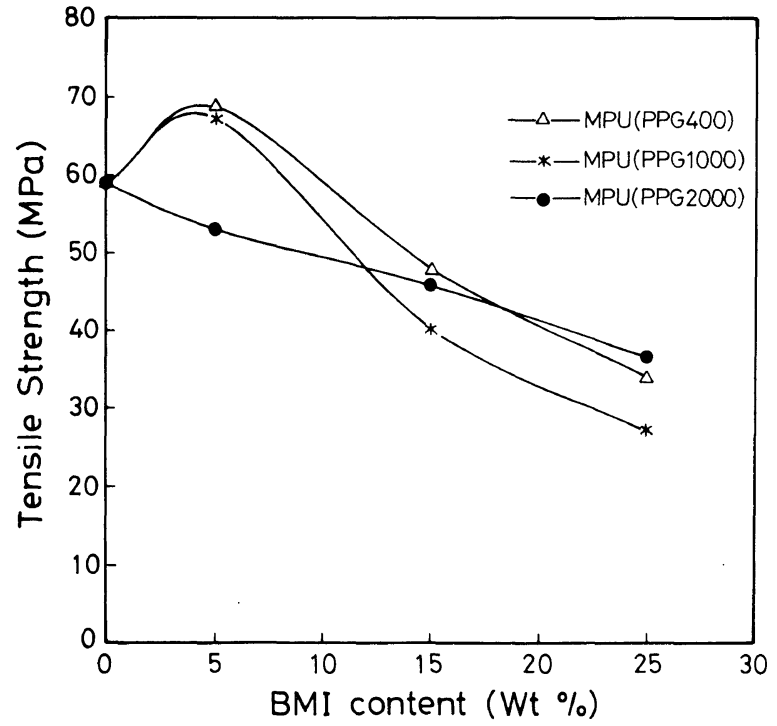

Figure 4. Tensile strength of $\mathrm{BMI} / \mathrm{epoxy} / \mathrm{graft}(\mathrm{EGMPU}(\mathrm{PPG}))-\mathrm{IPN}$ vs. BMI content $(\mathrm{BMI} /$ epoxy/coupling agent $=5 / 95 / 10,15 / 85 / 10$, 25/75/10 wt. ratio): $(\triangle) \mathrm{BMI} /$ epoxy/graft(EGMPU(PPG400))-IPN; ( *) BMI/epoxy/graft(EGMPU(PPG1000))-IPN; graft(EGMPU(PPG2000))-IPN.

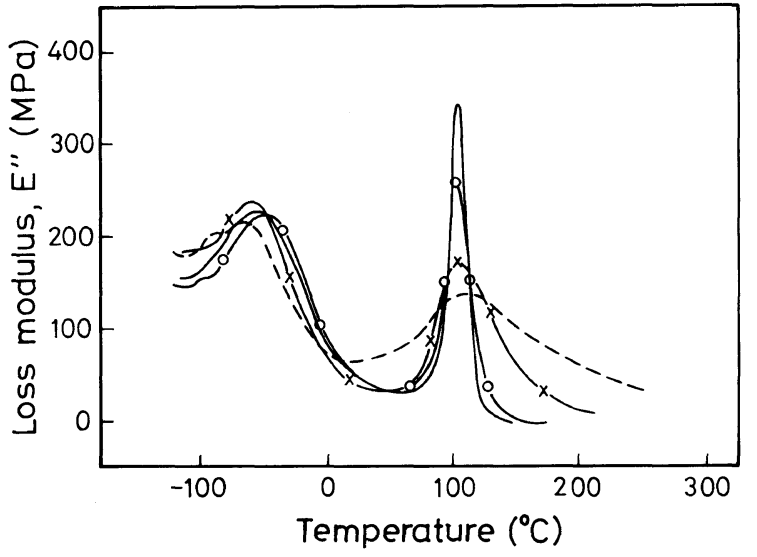

Figure 5. Temperature dependence of loss modulus $\left(E^{\prime \prime}\right)$ of $\mathrm{BMI} /$ epoxy/graft(EGMPU(PPG1000))-IPN at various BMI/epoxy

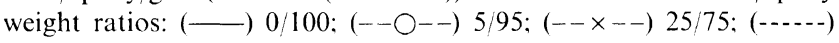
$50 / 50$.

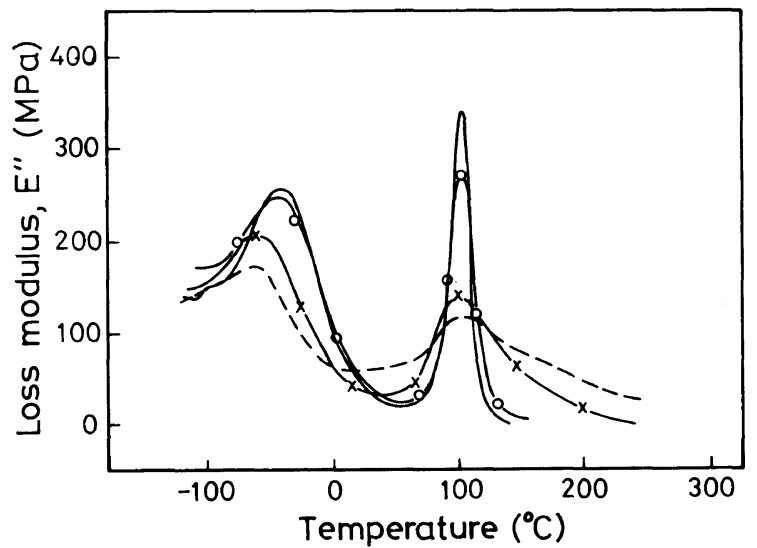

Figure 6. Temperature dependence of loss modulus $\left(E^{\prime \prime}\right)$ of $\mathrm{BMI}$ epoxy/graft(EGMPU(PPG2000))-IPN at various BMI/epoxy weight ratios: $(-)$ 0/100; (--O--) 5/95; (-- x--) 25/75; (-----) 50/50.

from $10 \mathrm{wt} \%$ EGMPU based on PPG (EGMPU(PPG)) coupling agent (Figure 4) showed maxima with increasing BMI content. Tensile strength was maximum at a 


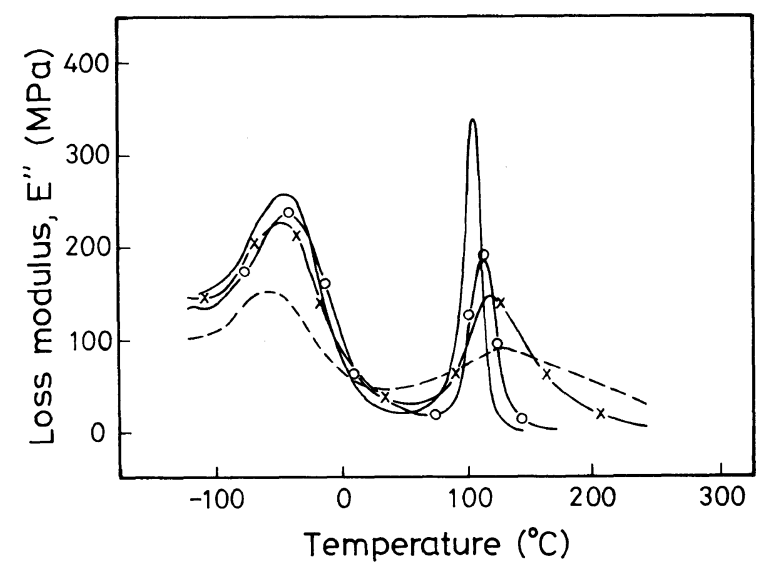

Figure 7. Temperature dependence of loss modulus $\left(E^{\prime \prime}\right)$ of BMI epoxy/graft(EGMPU(PBA1000))-IPN at various BMI/epoxy weight ratios: (-) $0 / 100 ;\left(--O_{--)} 5 / 95 ;(--\times--) 25 / 75 ;(\cdots--) 50 / 50\right.$.

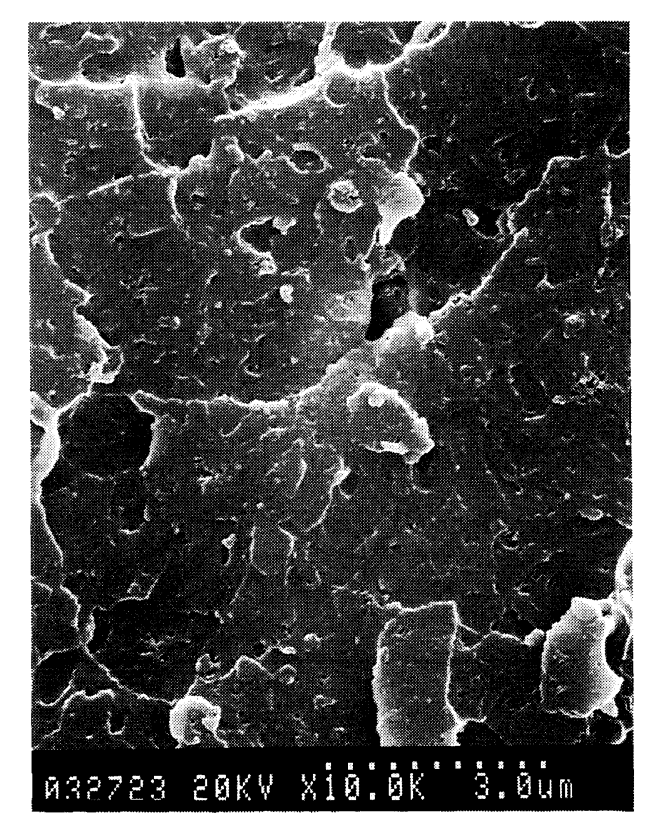

(a)

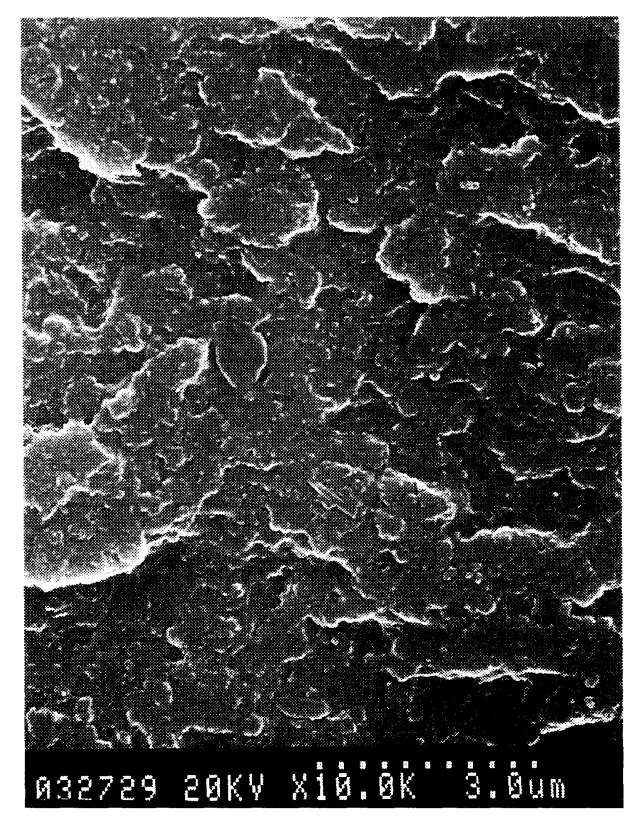

(b)

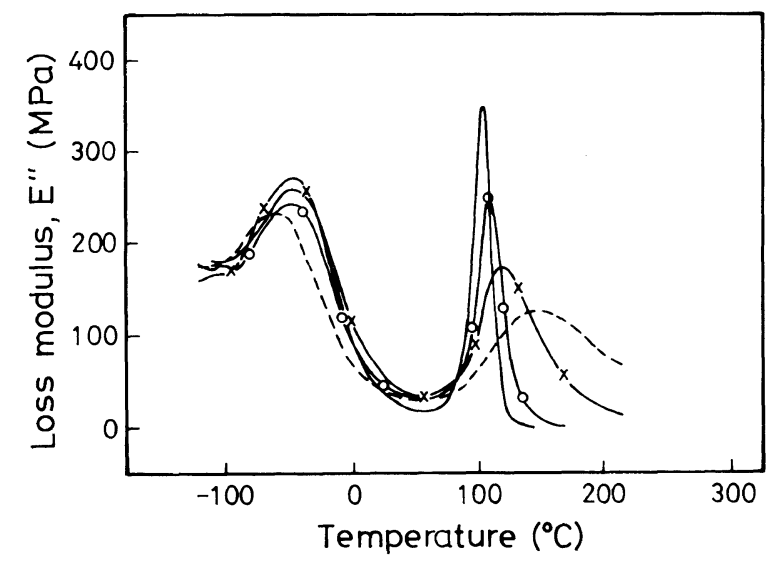

Figure 8. Temperature dependence of loss modulus $\left(E^{\prime \prime}\right)$ of BMI/epoxy/graft(EGMPU(PBA2000))-IPN at various BMI/epoxy weight ratios: (—) 0/100; (-- ---$)$ 5/95; (-- ×--) 25/75; (--.--) $50 / 50$.

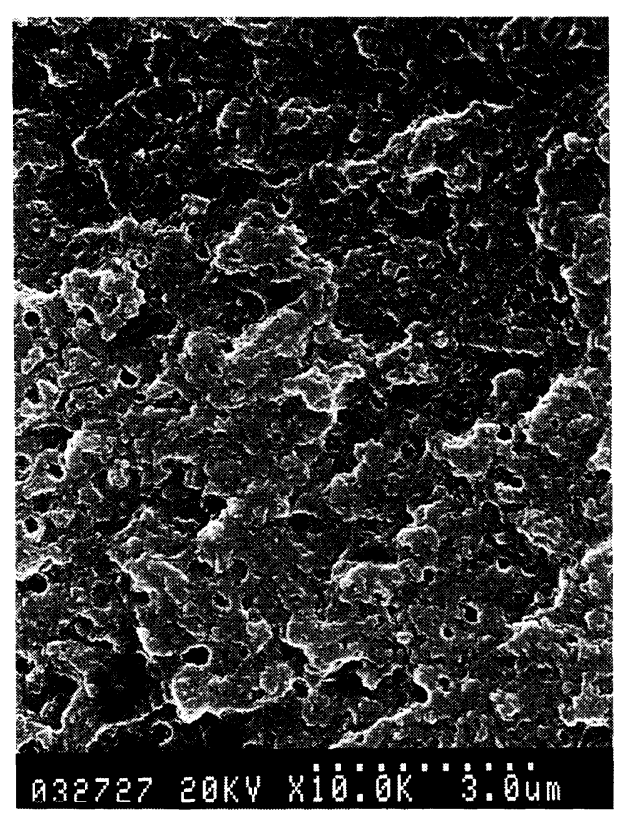

(c)

Figure 9. Scanning electron microphotographs (SEM) of BMI/ epoxy/graft(MPU(PPG2000))-IPNs at various BMI/epoxy ratios: (a) $5 / 95$; (b) $25 / 75$; (c) $50 / 50$.

BMI/epoxy weight ratio of 5/95. Maximum values were not found and the tensile strength was markedly higher than when grafting reactions were neglected (i.e., BMI/ epoxy IPN, $<20 \mathrm{MPa})$. When BMI exceeded $7 \mathrm{wt} \%$, BMI/epoxy IPN were too brittle to be tested. This improvement in tensile strength was possibly due to increased interpenetration as a result of the graft structure. The greater strength can be attributed to better compatibility between the BMI and epoxy networks by EGMPU grafting than when grafting is neglected.

\section{Dynamic Mechanical Properties}

Figures 5-8 present the DMA scanned for the BMI/epoxy/graft(EGMPU)-IPNs with $10 \mathrm{wt} \%$ EGMPU coupling agent and various BMI amounts. The loss modulus versus temperature curve for the pure epoxy exhibits two distinct transition peaks: one at high temperature, $105^{\circ} \mathrm{C}$ (called the " $\alpha$ transition" in this 
article), and the other at low temperature, $-53^{\circ} \mathrm{C}$ (the " $\beta$ transition"). Regarding the transition peak of the BMI network in BMI/epoxy/graft(EGMPU)-IPNs, DMA showed that the cured BMI network had high crosslinking density and high glass transition temperature $\left(T_{\mathrm{g}}\right)(18-20)$. According to Figures 5 and 6 , incorporating the $10 \mathrm{wt} \%$ EGMPU coupling agent based on PPG1000 and PPG2000 in the BMI/epoxy/graft(EGMPU)-IPNs caused no shifting of the $\alpha$-transition peak which peak continuously decreased in intensity with BMI content. However, the molecular weight of EGMPU coupling agent based on PPG (MPU(PPG)) did not influence transition for the BMI/epoxy/graft(EGMPU)IPNs. This implies that EGMPU(PPG) coupling agents are not incorporated into the BMI and epoxy networks of BMI/epoxy/graft(EGMPU)-IPNs. The EGMPU(PPG) coupling agent had poor grafting effect due to lower compatibility between the BMI and epoxy networks in the BMI/epoxy/graft(EGMPU)-IPN. Thus, the BMI/epoxy/ $\operatorname{graft}(\mathrm{EGMPU})-\mathrm{IPNs}$ with $10 \mathrm{wt} \%$ EGMPU(PPG) coupling agent has heterogeneous morphology (Figure 9). According to Figures 5 and 6, regardless of the molecular weight of EGMPU(PPG), the coupling agent based on PPG 1000 and PPG2000, the $\alpha$-transition peak broadens and decreases in intensity with BMI content for $\mathrm{BMI} /$ epoxy/graft(EGMPU)-IPNs. This is attributed to cured BMI and epoxy networks formation in IPN. The cured BMI network has rigidity, high crosslinking density and low loss modulus, $E^{\prime \prime}$. Therefore, the BMI/ epoxy/graft(EGMPU)-IPNs with $10 \mathrm{wt} \%$ EGMPU coupling agent based on PPG1000 and PPG2000 decreases the loss modulus $\left(E^{\prime \prime}\right)$ of the $\alpha$-transition peak when BMI is added (Figures 5 and 6).

For BMI/epoxy/graft(EGMPU)-IPNs based on EGMPU(PBA) coupling agent, the molecular weight of the EGMPU(PBA) coupling agent does not influence transition. Figures 7 and 8 indicate that $\alpha$-transition peaks for BMI/epoxy/graft(EGMPU)-IPNs based on EGMPU(PBA) coupling agent shift to a high temperature and intensity decreases with BMI. EGMPU(PBA)based BMI/epoxy graft-IPNs have higher $\alpha$-transition temperatures than EGMPU(PPG)-based BMI/epoxy graft-IPNs. The temperature of $\alpha$-transition peak of EGMPU(PBA)-based BMI/epoxy graft-IPNs increases with BMI. This suggests that the EGMPU(PBA) coupling agent has better grafting effect between BMI and epoxy networks in BMI/epoxy/graft(EGMPU)-IPN than EGMPU(PPG) coupling agent. Cured BMI and cured epoxy networks form IPN structures in the BMI/epoxy/ graft(EGMPU)-IPN with $10 \mathrm{wt} \%$ EGMPU(PBA) coupling agent. Thus, the $\alpha$-transition peak broadens and decreases in intensity with BMI (Figures 7 and 8).

\section{CONCLUSIONS}

The present results demonstrate that the tensile strength of BMI/epoxy/graft(EGMPU)-IPN may have maximum tensile strength at a $\mathrm{BMI} /$ epoxy weight ratio 5/95. Greater strength is possible by EGMPU coupling than when grafting is neglected. BMI/epoxy/graft(EGMPU)-IPNs obviously form IPN structures. For $\mathrm{BMI} /$ epoxy/graft(EGMPU)-IPNs, the EGMPU(PBA) coupling agent has better grafting effect due to higher compatibility between BMI and epoxy networks than the EGMPU(PPG) coupling agent.

Acknowledgments. The authors thank the National science Council of the Republic of China for financially supporting this research under Contract No. NSC 85-2216-E-197-002. Prof. K. H. Hsieh in Department of Chemical Engineering, National Taiwan University, Taipei, Taiwan is also appreciated for his valuable assistance.

\section{REFERENCES}

1. A. J. Curtius, M. J. Covitch, D. A. Thomas, and L. H. Sperling, Polym. Eng. Sci., 12, 101 (1972).

2. S. C. Kim, D. Klempner, K. C. Frisch, W. Radigan, and H. L. Frisch, Macromolecules, 9, 258 (1976).

3. D. Klempner, Angew. Chem., 17, 97 (1978).

4. L. W. Nielsen, Macromol. Chem., 4, 76 (1970).

5. L. H. Sperling and D. W. Friedmen, J. Polym. Sci., A--2, 7, 425 (1970).

6. V. Huelck, D. A. Thomas, and L. H. Sperling, Macromolecules, 5, 340 (1972).

7. K. C. Frisch, D. Klempner, and S. K. Mukherjes, J. Appl. Polym. Sci., 18, 689 (1974)

8. L. H. Sperling, "Interpenetrating Polymer Networks and Materials," Plenum Press, New York, N.Y., 1981, p 99

9. C. E. Sroog, A. L. Endreg, S. V. Abramo, C. S. Beer, W. M. Edward, and K. L. Oliver, J. Polym. Sci., Polym. Chem. Ed., 3, 1373 (1965).

10. I. K. Varma, G. M. Fohlen, and J. A. Parker, Macromol. Sci. Chem., A19, 209 (1983).

11. A. V. Galanti and D. A. Scola, J. Polym. Sci., Polym. Chem. Ed., 19, 451 (1981).

12. H. Lee and K. Neville, Ed., "Handbook of Epoxy Resins," Mcgraw-Hill, New York, N.Y., 1967.

13. C. Hepburn, "Polyurethane Elastomer," Applied Science Publishers, New York, N.Y., 1982, p 280.

14. K. H. Hsieh and J. L. Han, J. Polym. Sci., Part B, Polym. Phys., 28, 623 (1990).

15. K. H. Hsieh and J. L. Han, J. Polym. Sci., Part B, Polym. Phys., 28. 783 (1990).

16. J. L. Han, Y. C. Chern, K. Y. Li, and K. H. Hsieh, J. Appl. Polym. Sci., (1998), accepted.

17. J. L. Han and K. Y. Li, J. Appl. Polym. Sci., (1998), accepted.

18. T. Pascal, R. Mevcier, and B. Sillion, Polymer, 30, 739 (1989).

19. D. C. Liao, K. H. Hsieh, and S. C. Kao, J. Polym. Sci., Polym. Chem. Ed., 33, 481 (1995).

20. D. C. Liao and K. H. Hsieh, J. Polym. Sci., Polym. Chem. Ed., 32, 1665 (1994). 